\title{
SENTIDO Y ALCANCE DE ALGUNAS DISTINCIONES SOBRE LA INVALIDEZ DE LAS LEYES
}

Sumario: I. La equivocidad de la distinción entre nulidad y anulabilidad. II. La distinción entre invalidez e inexistencia: 1) sentido y problemas teóricos de la distinción; 2) ¿dos clases de reglas sobre la producción jurídica?; 3) ventajas y dificultades del concepto de inexistencia. III. Conclusiones.

a terminología sobre la invalidez de las leyes no es uniforme entre los juristas y, lo que es peor, seguramente tampoco el significado de los conceptos que utilizan. Las nociones de ineficacia, inexistencia, invalidez, nulidad o anulabilidad se usan muchas veces de modo confuso o equívoco. No se intentará dilucidar aquí todas las cuestiones implicadas, pero sí estudiar con algún detenimiento el sentido, alcance y justificación de dos distinciones habituales. La primera es la que se establece entre nulidad y anulabilidad, donde no siempre queda claro si se alude al género de vicio, al régimen de invalidación (procedimiento, jurisdicción competente, etc.) o a la eficacia de las decisiones que declaran o establecen la invalidez de la ley. La segunda, y en la que centraremos más nuestra atención, es la que algunos sugieren entre inexistencia e invalidez con el aparente propósito de postular dos modelos distintos de invalidación de las leyes.

\section{LA EQUIVOCIDAD DE LA DISTINCIÓN ENTRE NULIDAD Y ANULABILIDAD}

Es una deuda habitualmente reconocida por las distintas dogmáticas que sus respectivas teorías de la nulidad se han construido a partir de la elaborada por el Derecho civil sobre la eficacia de los negocios jurídicos, hasta el punto de que esta última pasa por ser la «teoría general» exportable, con mayores o menores cautelas, a cualquier disciplina jurídica ${ }^{1}$. Muy resumidamente, dicha teoría general opera las siguientes distinciones: 1) inexistencia:

\footnotetext{
${ }^{1}$ A título de ejemplo, E. García de Enterría y T. R. Fernández, Curso de Derecho Administrativo, I, 4a edic., Madrid, Civitas, 1987, pp.563 ss. No faltan, sin embargo, quienes, reconociendo esa deuda, insisten en las peculiaridades de su objeto normativo y en la necesidad de elaborar explicaciones independientes. Así, también como ejemplo, J. L. Villar Palasí y J. L. Villar Ezcurra, Principios de Derecho Administrativo, II, Madrid, Servicio de Publicaciones de la Universidad Complutense, 2a edic. 1987, pp. 157 ss.; V. Gimeno, J. Garberí, N. González Cuéllar, Derecho Procesal Administrativo, Valencia, Tirant lo Blanc, 1991, pp. 260 ss.
} 
un negocio sería inexistente cuando falta absolutamente cualquiera de los elementos esenciales que su naturaleza o tipo exige. La inexistencia produce una ineficacia insanable, ipso iure, e impide que el negocio despliegue efectos ab initio; 2) nulidad: sus consecuencias son en la práctica las mismas que se predican para la inexistencia, y tampoco existe ninguna acción procesal específica que permita distinguir ambas figuras. Con todo, suele reservarse el nombre de nulidad para los actos contrarios a las normas imperativas, o sea, los que violan algún precepto objetivo no disponible; 3) anulabilidad: va dirigida a la protección de intereses disponibles de un determinado sujeto, de manera que éste puede optar por impugnar el negocio alegando la invalidez o sanarlo mediante confirmación. En verdad, la distinción entre inexistencia y nulidad no es pacífica en la doctrina iuscivilista. Para muchos la figura de la «inexistencia» carece de sentido teórico, al no dar lugar a consecuencias jurídicas distintas de la nulidad; otros opinan, sin embargo, que, en sentido estricto, para que un negocio pueda ser nulo ha de ser antes existente ${ }^{2}$. En realidad, y aunque no se utilice esta terminología, parece que la inexistencia supone la violación de las reglas constitutivas que definen el negocio, mientras que la nulidad sanciona la infracción de normas imperativas, mandatos o prohibiciones ${ }^{3}$. Con todo, aunque estas distinciones puedan conservar alguna utilidad «general», su aplicación al ámbito de las normas, y más concretamente de las leyes, no puede hacerse sin tener en cuenta las diferentes ideas y conceptos sobre los que las teorías iusprivatista y iuspublicista se han construido. No cabe detenerse en estos aspectos, que, entre otras cosas, requerirían analizar las muy distintas consecuencias que se derivan del principio de autonomía de la voluntad que rige el derecho privado y las que se deducen del concepto de potestad reglada que gobierna el Derecho público. En cualquier caso, y en parte como proyección de esa diferencia, difícilmente se puede intentar construir una teoría general o común de las nulidades jurídicas, de la que la elaborada por el Derecho privado sería una especie de ejemplo paradigmático. Los actos jurídicos no son realidades naturales, sino convencionales o artificiales, y por eso cada tipo de acto (los negociales y los normativos, por ejemplo) estará

${ }^{2}$ Puede verse L. Díez-Picazo, Fundamentos de Derecho civil patrimonial, I, Madrid, Tecnos, 1986, pp. 313 ss.; J. Delgado, «De la nulidad de los contratos», Comentario al Código Civil, II, Madrid, Min. de Justicia, 1991, pp. 541 ss.; A. Gordillo, «Nulidad, anulabilidad e inexistencia», Centenario del Código Civil, Madrid, R. Areces, 1990, pp. 935 ss.; M. García Amigo, Teoría General de las Obligaciones y Contratos, Madrid, McGraw-Hill, 1995, pp. 399 ss.

3 A veces incluso se emplean expresiones que recuerdan la conocida y discutida distinción entre reglas constitutivas y normas de conducta; así, cuando se clasifican los requisitos del contrato en constituyentes y de conducta, cuya vulneración daría lugar respectivamente a la inexistencia y a la nulidad. Vid., M. García Amigo, op. cit. Sobre la distinción entre reglas constitutivas y normas de conducta volveremos en el epígrafe II. 
disciplinado por el régimen que en cada caso establezca el Derecho; y en particular, el régimen de nulidad de cada tipo de acto será también el que el ordenamiento determine.

La doctrina iuspublicista, sin embargo, ha tendido a adoptar para la invalidez de las normas -y en particular de la ley- la terminología de la doctrina iusprivatista de las nulidades, lo que tal vez haya contribuido a generar una cierta confusión sobre las claves de la invalidez. Pero esa confusión no proviene sólo de la trasposición de conceptos elaborados en un contexto (el de la Pandectística) y para un ámbito jurídico distinto al del Derecho público, sino también, y sobre todo, de que estos conceptos han sido usados para hacer referencia a cuestiones bien diversas. En concreto, la dicotomía nulidad- anulabilidad se utiliza indistintamente para identificar: a) el régimen de validez de la ley; b) el régimen de invalidación y de eficacia de la ley inconstitucional; y c) el régimen de eficacia de los eventuales actos jurídicos declarativos de la invalidez. Pero, antes de señalar a qué hace referencia cada uno de estos tres regímenes, conviene una breve aclaración sobre lo que entendemos por validez.

Entre los distintos conceptos de validez, y con independencia de si requieren o no la adopción de un cierto punto de vista externo o interno ${ }^{4}$, entenderemos aquí que un juicio de validez es un juicio descriptivo acerca de una norma, en el sentido de que en principio no implica ninguna recomendación moral de obediencia, sino que sólo informa de su existencia en el sistema. Por tanto, validez significa existencia de una norma o pertenencia de la misma al ordenamiento $^{5}$. Una cuestión distinta -pero conectada con ésta- es la de encontrar el criterio para poder afirmar que una norma es válida. Dejando aparte el problema de las fuentes «extra ordinem» (cuya validez está vinculada a su eficacia), el criterio de validez que utilizaremos entiende que una norma es válida, existe o pertenece al ordenamiento, si reúne todos los requisitos establecidos para su creación por las normas sobre la producción jurídica (en adelante NSPJ) $)^{6}$

\footnotetext{
${ }^{4}$ Sobre las distintas acepciones del término validez, vid., por todos, C. S. Nino, La validez del Derecho, Buenos Aires, Astrea, 1985; E. Bulygin, «Validez y positivismo», en C. Alchourrón y E. Bulygin, Análisis lógico y Derecho, Madrid, CEC, 1991, pp. 499 ss.; L. Prieto, «Validez, eficacia y justicia», (J. Betegón y otros) Lecciones de teoría del Derecho, Madrid, McGraw-Hill (en prensa).

${ }^{5}$ H. Kelsen, Teoría pura del Derecho (1960), 2a edic., trad. R. Vernengo, México, UNAM, 1979,p. 23.

${ }^{6}$ N. Bobbio lo expresa con claridad: las NSPJ ofrecen los criterios necesarios y suficientes para «reconocer» cuáles son las normas válidas del sistema, «Per un lessico di teoria generale del diritto» (1975), ahora en Contributi ad un dizionario giuridico, Turín, Giappichelli, 1994, cap. XII, p. 240.
} 
Partiendo de este concepto de validez, la distinción que media entre los tres regímenes arriba mencionados es la siguiente:

a) Régimen de validez: conjunto de condiciones establecidas por las NSPJ para la validez de las leyes y los actos legislativos. La infracción de cada una de estas condiciones de validez da lugar a un «vicio» de la ley. Por ello, entre las condiciones de validez y los vicios de la ley no hay una diferencia sustantiva.

b) Régimen de invalidación y de eficacia de la ley inválida: determina quién (o quiénes) tienen competencia para enjuiciar la validez de la ley y en qué condiciones ha de ejercerse esta competencia; es decir, determina el sistema de control de la validez. El régimen de invalidación influye en la determinación del régimen de eficacia de la ley inválida.

c) Régimen de eficacia de los actos declarativos de la invalidez: determina qué efectos jurídicos se atribuyen a los eventuales actos declarativos de la invalidez de las leyes.

La distinción entre nulidad y anulabilidad se ha utilizado para hacer referencia a cada uno de estos regímenes, dando así lugar a una cierta ambigüedad y confusión.

a) Los términos nulidad y anulabilidad se han utilizado para identificar el régimen de validez de la ley; o más exactamente, para elucidar qué tipos de vicios deben ser concebidos en clave de nulidad y cuáles en clave de anulabilidad. Sobre esta cuestión se volverá en el epígrafe II, a propósito de la distinción entre inexistencia e invalidez. Sirva por ahora lo que sigue. La invalidez de la ley se determina por la concurrencia de algún vicio; o sea, por su disconformidad con las normas que establecen sus condiciones de validez. Como cabe distinguir cuatro grandes tipos de normas que instauran condiciones de validez (normas de competencia formal, de procedimiento, de competencia material y de contenido), cabe distinguir también cuatro grandes tipos de vicios (vicio de incompetencia formal, de forma o procedimiento, de incompetencia material y de contenido) ${ }^{7}$. Quienes piensan que no todos estos tipos de normas establecen condiciones necesarias para la existencia de la ley, proyectan la distinción nulidad-anulabilidad sobre la naturaleza de la norma violada. Así, en este contexto se hablaría de nulidad (o «inexistencia») si el vicio deriva de la violación de una norma que establece condiciones necesarias de existencia. Se hablaría, en cambio, de anulabilidad (o «invalidez», en sentido restringido) si el vicio deriva de la violación

\footnotetext{
${ }^{7}$ R. Guastini sostiene que son cinco las clases de NSPJ y, por tanto, cinco las clases de vicios, añadiendo a los mencionados la «incompetencia material negativa», consecuencia de la violación de normas que establecen reservas, Distinguendo. Studi di teoria e metateoria del diritto, Turín, Giappichelli, 1996, pp. 270 y 277. Con todo, a los efectos de nuestro estudio, la violación de las reservas equivale a un vicio de incompetencia material.
} 
de una norma que no establece condiciones de existencia, sino sólo limitaciones de la actividad normativa.

b) Los términos nulidad y anulabilidad han trascendido también al ámbito del Derecho público para dar cuenta del régimen de invalidación y de eficacia de laley inconstitucional. Cabe hablar aquí de nulidad para hacer referencia al control difuso de validez, porque es un control per incidens en el que cualquier juez puede inaplicar la ley que estime inconstitucional: la ley inválida carece de eficacia vinculante. En cambio, en los sistemas de control de validez concentrado, la ley inválida goza de una presunción de legitimidad, y por consiguiente su eficacia queda preservada entretanto no se pronuncie el órgano competente. No es nula, se dice, sino anulable, porque mientras no sea anulada es eficaz ${ }^{8}$. En suma, en este contexto, nulidad y anulabilidad hacen referencia al régimen de invalidación y eficacia de la ley inconstitucional, pero no a la «calidad» del vicio, pues son éstas dos cuestiones entre las que no existe una conexión necesaria ${ }^{9}$, aunque obviamente cabe postular que los remedios más rápidos se reserven para los vicios más graves.

c) Por último, la distinción entre nulidad y anulabilidad se reproduce en ocasiones a propósito de la eficacia de los actos jurídicos que determinan la invalidez de la ley. Suele hablarse de nulidad cuando tales actos tienen efectos retroactivos (ex tunc), y se dicen entonces declarativos de la invalidez; se habla de anulabilidad cuando tienen efectos pro futuro (ex nunc), y se dicen entonces constitutivos de la invalidez ${ }^{10}$. Pero adviértase que el momento

\footnotetext{
${ }^{8}$ Incluso cabe que en un mismo sistema jurídico operen conjuntamente ambos modelos. Así fue interpretada la Constitución española por E. García de Enterría, al sostener que el principio general que reserva el enjuiciamiento de las leyes al Tribunal Constitucional encuentra una excepción en aquéllas que violen el contenido esencial de derechos fundamentales, donde jugaría la inaplicación de la ley por el juez ordinario, "La Constitución como norma jurídica», en A. Predieri y E. García de Enterría, La Constitución española de 1978, Madrid, Civitas, 1980, p. 126.

${ }^{9}$ La opción por uno u otro sistema de invalidación, en efecto, se opera por consideraciones que son ajenas a la «calidad» de la invalidez, que por sí misma sólo significa la infracción de normas que establecen requisitos para la validez. Optar por uno u otro sistema de invalidación depende de los fines que se persigan. Así, se ha interpretado que la implantación de un control difuso de invalidez responde (sólo) a las exigencias de los derechos del individuo frente al Estado, mientras que el control concentrado responde (también) a las exigencias de la ley, es decir, de la política, vid. G. Zagrebelsky, El Derecho dúctil (1992), trad. M. Gascón, Madrid, Trotta, 1995, p. 61 ss.

10 Este enlace entre nulidad/retroactividad y anulación/irretroactividad se aprecia en la siguiente afirmación: «entrañando la oposición entre norma impugnada y Constitución un supuesto de nulidad absoluta, los efectos de la sentencia deberían retrotraerse», J. Arozamena, «El recurso de inconstitucionalidad», en El Tribunal Constitucional, Madrid, IEF, 1981, vol. 1I, p. 171. O también: la nulidad «se produce ipso iure con la consiguiente eficacia ex tunc», R. Bocanegra, El valor de las sentencias del TC, Madrid, IAL, 1982, p. 243, En el mismo sentido, E. García de Enterría, La Constitución como norma, Madrid, Civitas, y edic., 199 1, pp. 55 ss.
} 
a partir del cual opera la invalidez es independiente del tipo de vicio y (en parte) del modelo de control o fiscalización.

La ambigüedad de los términos nulidad y anulabilidad que se desprende de estos tres significados se torna confusión cuando se entremezclan todos ellos en una suerte de intento unificador. Así, se sugiere, la invalidez de la ley se concibe en clave de nulidad si el vicio que la provoca determina su inexistencia, razón por la cual la ley inválida no tendría eficacia vinculante para los jueces (que podrán inaplicarla) y las eventuales sentencias que determinen su invalidez serán necesariamente declarativas (tendrán efectos ex tunc). Por el contrario, la invalidez de la ley se concibe en clave de anulabilidad si el vicio que la provoca no determina su inexistencia, razón por la cual la ley inválida tendrá eficacia vinculante para los jueces hasta que el órgano competente no constituya su invalidez y las sentencias de este último tendrán efectos ex nunc ${ }^{11}$.

A mi juicio, esta confusión ${ }^{12}$ puede (y debe) ser deshecha en los tres planos examinados. Ante todo, en el plano del régimen de validez o de los tipos de vicios. El régimen de validez de las normas es el que determinan las normas sobre fuentes del sistema y cada concreto ordenamiento puede efectuar una distinción entre los diversos vicios, configurando unos como nulidad y otros como anulabilidad; pero en ausencia de tales distinciones normativas todos los vicios comparten el mismo régimen. En suma, la distinción entre vicios de nulidad (o «inexistencia»), y vicios de anulabilidad (o «invalidez»), carece de sentido si normativamente no se ha configurado. De ello nos ocuparemos en el epígrafe siguiente.

La segunda confusión que hay que deshacer es la que vincula -a través de los conceptos de nulidad y anulabilidad- el régimen de invalidación y eficacia de la norma inválida con el régimen de validez. El régimen de invalidación es el sistema de control (concentrado, difuso o mixto) de validez

${ }^{11}$ Por ejemplo, J. Almagro caracteriza el sistema difuso como aquel en que el juez ordinario dicta «una sentencia declarativa de nulidad», que «despliega típicos efectos retroactivos»; mientras que el sistema austriaco persigue «la anulación de la ley» y «la sentencia que declara la inconstitucionalidad tiene, pues, carácter constitutivo y proyecta sus efectos "ex nunc"», Justicia constitucional, Madrid, Dykinson, 1980, pp. 179 ss. La descripción puede ser acertada, pero adviértase cómo el binomio nulidad/anulabilidad parece enlazarse «naturalmente» a cuestiones en sí mismas diferentes y que pueden ser objeto de regulaciones dispares.

${ }^{12}$ La confusión aludida se muestra sobre todo en la carencia de eficacia explicativa de este intento sistematizador, pues las cosas en muchos sistemas jurídicos no son exactamente así. Sin ir más lejos, esto es lo que ocurre en el Derecho español, donde la ley inválida tiene eficacia vinculante para los jueces ordinarios (razón por la cual se hablaría de anulabilidad), pero, en ausencia de regulación constitucional y según se interpretan los arts. 39 y 40 LOTC, las sentencias de inconstitucionalidad del TC se consideran declarativas de la invalidez (razón por la cual procedería hablar de nulidad). Sobre esto último, R. Bocanegra, El valor de las sentencias..., cit., pp. 235 ss., esp. p. 243. 
de la ley, lo que es independiente del régimen de validez de la misma, que tan sólo hace referencia a las causas de invalidez. Brevemente: un mismo régimen de validez puede ir acompañado de un distinto régimen de invalidación y eficacia de la ley inválida.

Finalmente, por lo que se refiere al régimen de eficacia de los actos declarativos de la invalidez, se trata asimismo sólo de la elección de uno u otro modelo, cuestión que también es independiente del régimen de validez de la ley, así como de su régimen de invalidación, al menos en parte ${ }^{13}$. Brevemente: un mismo régimen de validez y/o de invalidación y eficacia de la ley inválida puede ir acompañado de un diferente régimen de eficacia de los actos declarativos de invalidez. Pero además, en este caso, incluso la terminología usada (actos declarativos/actos constitutivos) puede resultar más confundente que aclaratoria. En efecto, en sentido riguroso, la invalidez de la ley tan sólo podrá ser eventualmente «declarada» y nunca «constituida» por los órganos competentes, pues el vicio se produjo antes del acto de declaración de la invalidez. Otra cosa es el régimen de eficacia de esas declaraciones de inconstitucionalidad; es decir, el tipo de efectos (ex tunc o ex nunc) que se les anuden. Tal vez podría decirse que, como regla general, los efectos que derivan de los actos declarativos de invalidez deberían retrotraerse al momento en que surgió la causa de invalidez. Pero sólo como regla general, pues tales efectos serán siempre los que determinen las normas superiores del ordenamiento, que desde luego podrán disponer (o permitir) cosa distinta: efectos pro futuro.

Ahora bien, si éstas son cuestiones independientes pueden recibir soluciones diferentes en función de los valores e intereses que se quieran proteger. En este sentido, como parece evidente que anudar a la declaración de nulidad efectos retroactivos puede acarrear consecuencias perturbadoras (pues obligaría a tener por inexistentes cuantas situaciones jurídicas hubieran nacido al amparo de la ley inválida), incluso los sistemas que han optado por la retroactividad suelen mitigar la rigidez de estas consecuencias estableciendo excepciones importantes a esa retroacción ${ }^{14}$. Pero cabía llegar más lejos y, de hecho, se ha llegado: se viene abriendo paso una doctrina según la cual los efectos que haya podido desplegar la ley mientras no ha sido declarada inválida podrán ser respetados por los actos que declaren su invalidez (irretroactividad), en atención a que ha gozado de una «apariencia

\footnotetext{
13 «En parte» porque, aunque la eficacia de las declaraciones, del TC u órgano ad hoc similar puede concebirse como retroactiva o como prospectiva, no ocurre igual con el juez ordinario: sería absurdo que éste no diese algún efecto retroactivo a la nulidad, pues entonces no pondría remedio al asunto que se le somete.

${ }^{14}$ Esto hace la LOTC al establecer que las declaraciones de inconstitucionalidad no afectarán a la cosa juzgada (art. 40.1).
} 
de validez» capaz de generar una confianza ${ }^{15}$. Desde luego, esta conclusión no se obtiene de manera incuestionable. Se trata tan sólo de una construcción (doctrinal y jurisprudencial) apoyada en razones de orden práctico que se juzgan atendibles en el ordenamiento. Pues bien, si la «apariencia de validez» es una buena razón para separarse del régimen de eficacia (retroactiva) establecido en un sistema, la «falta absoluta de apariencia de validez» podría ser también un buen argumento para impulsar una nueva figura: la «inexistencia». Con ella se trata de reconstruir la ecuación que hemos venido negando en el plano teórico, pero que puede tener un sentido práctico; a saber: delimitar cierto tipo de vicios que deberían (o podrían) hacerse acreedores a un particular régimen de invalidación y de eficacia de los actos declarativos de la invalidez. De ello nos ocuparemos en las páginas que siguen.

\section{LA DISTINCIÓN ENTRE INVALIDEZ E INEXISTENCIA}

\section{1) Sentido y problemas teóricos de la distinción}

Aunque el uso de estas expresiones no es homogéneo, aquí hemos identificado «existencia» con «validez» o pertenencia al sistema, de manera que, desde este planteamiento teórico, la distinción que ahora proponemos entre inexistencia e invalidez resulta del todo inviable. Con todo, conceptualmente, sigue teniendo sentido plantearse la posibilidad de esta distinción, sugiriendo que una cosa es que la norma exista (pertenezca al ordenamiento o sea recognoscible como parte de él) pero esté «viciada», y otra diferente es que la norma no exista en absoluto porque no haya modo de reconocerla como parte del ordenamiento ${ }^{16}$. En el primer caso hablaríamos de invalidez stricto sensu; en el segundo, de invalidez-inexistencia, o inexistencia a secas.

${ }^{15}$ La manifestación más clara de esta tendencia la constituyen las declaraciones de mera inconstitucionalidad o inconstitucionalidad sin nulidad, que en el Derecho alemán han obtenido incluso respaldo normativo. Esta es también la senda que ha tomado el Tribunal Constitucional español, que con la STC 45/1989 ha iniciado una jurisprudencia prospectiva, secundando así al TS norteamericano (desde 1965), al TJCE (desde 1976) y al TEDH (desde 1979); vid. E. García de Enterría, «Un paso importante en el desarrollo de nuestra justicia constitucional», RDA, 61 (1989). Sobre la necesidad de matizar los rigores de la retroactividad mediante este tipo de sentencias se manifestaba ya en 1982 R. Bocanegra en El valor de las sentencias...; cit.; sobre el tema, también E Rubio Llorente, «La jurisdicción constitucional como forma de creación del Derecho», REDC, 22 (1988), pp. 36-37.

${ }^{16}$ Precisamente porque la distinción entre el uso irregular de un poder normativo y lo que no constituye en absoluto uso de tal poder está "profundamente arraigada en las intuiciones conceptuales de cualquiera que se ocupe del Derecho», M. Atienza y J. Ruiz Manero critican la concepción deóntica de las normas de competencia, en la medida en que no permite dar cuenta de esta distinción, "Adversus Pompeyanos. A proposito di alcune critiche alla nostra concezione delle regole che conferiscono poteri», en Analisi e Diritto. 1995, Turín, Giappichelli, 1995, p. 238. 
Por otra parte -y esto es sin duda lo fundamental- la distinción no es gratuita, ya que un acto o norma inexistente puede ser desconocido por cualquier operador jurídico, con independencia de que sea o no competente para enjuiciar su validez. Lo que pretendemos analizar en este epígrafe es si verdaderamente puede hablarse -y si es así, en qué casos- de la inexistencia como distinta de la invalidez.

Pero, antes de intentar responder a esta cuestión, es preciso advertir que la distinción entre inexistencia e invalidez presenta un interés en relación con las leyes notablemente superior al que ofrece en el ámbito del negocio privado y de la actuación administrativa. El particular que ha de hacer frente a un contrato o acto administrativo inexistente debe operar en lo fundamental como lo haría ante un acto nulo o no válido: la jurisdicción es la misma, también lo es la acción procesal y, por supuesto, los efectos de la sentencia. No ocurriría exactamente así con una ley que mereciese el calificativo de inexistente en un sistema de control de validez concentrado, donde el juicio se reserva a un procedimiento especialísimo que además suele culminar con una sentencia no plenamente retroactiva ${ }^{17}$. La categoría de la inexistencia cobra entonces interés, pues postularía, de un lado, que cualquier juez pudiese inaplicar lo que es sólo una apariencia de ley y, de otro, que una eventual declaración de inconstitucionalidad gozase del más vigoroso efecto retroactivo. En suma, el concepto de «inexistencia» de la ley operaría sobre dos aspectos: por un lado, sobre el régimen de eficacia de los actos declarativos de la invalidez, imponiendo la plena retroactividad, sin excepciones, de las eventuales sentencias del Tribunal Constitucional declarativas de la inexistencia; por otro lado -y sobre todo-, sobre el régimen de invalidación, imponiendo la apertura a un control jurisdiccional difuso. En lo sustancial, ello supondría la anulación del «privilegio jurisdiccional de la ley», que (en estos casos, pero sólo en éstos) perdería su fuerza vinculante frente a jueces y tribunales de la jurisdicción ordinaria. Pero, ¿es posible esta distinción?

En línea de principio, la distinción podría intentar apoyarse en consideraciones teóricas, normativas o prácticas. Teniendo en cuenta que la validez de la norma depende de su adecuación a las NSPJ, la distinción en el plano teórico requeriría acreditar que hay dos clases de NSPJ, unas generadoras de inexistencia y otras de invalidez de normas ya existentes. A su vez, en el plano normativo, sería preciso contar con un régimen jurídico propio para cada una de estas categorías que pudiera traducirse en dos modelos tripartitos (completos o incompletos): vicios de inexistencia, órgano y procedimiento

${ }^{17}$ Como ya se dijo, incluso en los sistemas donde la regla que rige la eficacia de estas sentencias es la retroactividad, se suelen introducir importantes excepciones a la misma. 
destinado a constatarla y efectos de la decisión; y vicios de invalidez, órgano y procedimiento destinado a constatarla y efectos de la decisión. Finalmente, desde un punto de vista práctico, se trataría de comprobar si existen buenas razones para construir, bien como propuesta de lege ferenda, bien por vía de interpretación cuando lo permita el sistema, dicha distinción o alguna de las consecuencias que pudieran venirle atribuidas.

Naturalmente, el problema normativo vendría resuelto si dentro de la categoría genérica de la invalidez de las leyes el sistema hubiera previsto dos modelos distintos, uno de invalidez en sentido estricto y otro de inexistencia. Ciertamente, aun cuando en el plano teórico no pudiera aceptarse la distinción si partimos de la concepción kelseniana de que validez equivale a existencia y de que ambas se miden igualmente por el criterio formal de pertenencia al ordenamiento $^{18}$, nada impediría que éste agrupase los diversos vicios en dos diferentes regímenes, que en un caso permitirían hablar de inexistencia y en otro de invalidez. Ahora bien, en ausencia de una clara determinación normativa, la cuestión es si cabe aportar argumentos teóricos en favor de la distinción comentada. Quizás la más lógica respuesta a este problema sería la de articular el binomio inexistencia-invalidez en función de la distinta naturaleza de las NSPJ violadas: de la infracción de un cierto tipo de normas derivaría la inexistencia; de la infracción del resto, la invalidez. Partiendo de este planteamiento, se trataría de ver si las distintas concepciones sobre la naturaleza de las NSPJ pueden ofrecer algún rendimiento de cara a esta distinción.

En el ámbito de la teoría jurídica se ha suscitado una viva polémica sobre la naturaleza de las NSPJ, o -por fidelidad a la terminología de los polemistas-

${ }^{18}$ En realidad, aunque en el plano teórico la identificación entre los conceptos de existencia y validez hace inviable la distinción comentada, lo cierto es que Kelsen fue consciente del problema y de las restricciones que el Derecho positivo puede imponer a las construcciones teóricas. Así, en uno de sus trabajos sobre la justicia constitucional, con mucha coherencia comienza reconociendo que «todo acto jurídico viciado debería ser considerado nulo, es decir, como algo que no es un acto jurídico», con la importante consecuencia de que cualquiera, autoridad pública o sujeto privado, podría desconocerlo sin más. Pero añade a renglón seguido que, en la práctica, los ordenamientos positivos imponen fuertes limitaciones a esa idea de nulidad y, sobre todo, al consiguiente «libre examen» por parte de los destinatarios de las normas, lo que ha dado lugar al régimen de anulabilidad, esto es, a la existencia de procedimientos específicos dirigidos a declarar la invalidez, con efectos retroactivos o no. Sin embargo, y esto no deja de ser llamativo en un positivista de estricta observancia, también las limitaciones establecidas por el Derecho positivo deben verse, a su vez, limitadas: «el Derecho positivo no puede jamás establecer que cualquier acto que se presente como acto de una autoridad pública deba sin más ser considerado como tal en tanto no sea anulado por irregularidad». Con todo, queda en una cierta nebulosa qué tipo de vicios dan lugar a la nulidad perceptible por todos y operativa para todos y cuáles, en cambio, pueden quedar sometidos al régimen de anulabilidad establecido por el Derecho positivo. H. Kelsen, «La garanzia giurisdizionale della costituzione», en $L a$ giustizia costituzionale, C. Geraci (ed.), Milán, Giuffrè, 1981, pp. 162 ss., esp., p. 163. 
«normas que confieren poderes» o «normas de competencia». Teniendo en cuenta que la discusión se centra básicamente en el análisis lógico de este tipo de normas, pueden distinguirse, sin ánimo de exhaustividad, tres grandes concepciones: la deóntica, la conceptualista o definicional y la de quienes, impugnando ambas posiciones, conciben estas normas como reglas que establecen condiciones necesarias de existencia.

Integran el primer grupo quienes sostienen que las reglas que confieren poderes tienen carácter deóntico; es decir, son prescripciones (o partes de prescripciones), ya se trate de mandatos, prohibiciones o permisos. Kelsen, Ross en 1958 y von Wright son ejemplos de esta posición. Para Kelsen, tales normas son fragmentos de las normas (independientes) creadas en el ejercicio de la competencia; es decir, son una de las condiciones a las que una norma independiente (un mandato que impone a los jueces la obligación de aplicar sanciones en ciertos casos) enlaza el acto coactivo. Para Ross, se trata de directivas dirigidas a los jueces a fin de que consideren como prescripciones los enunciados creados con arreglo a un procedimiento. Finalmente, para von Wrigth, las normas que confieren poderes («normas de orden superior», en su terminología) son normas permisivas, normas que permiten a una autoridad la producción de un acto normativo ${ }^{19}$.

A la concepción deóntica de las reglas que confieren poderes se opone la de quienes, poniendo de manifiesto la insuficiencia de la visión prescriptivista de «las piezas del Derecho» ${ }^{20}$, sostienen el carácter definicional, conceptual o constitutivo de las mismas. Una «definición»es un enunciado que establece el sentido en que se usa una expresión, y su función es contribuir a identificar las normas en que figuran los términos definidos ${ }^{21}$. Una regla conceptual o «constitutiva», en el sentido de J. Searle, es la que crea o define una forma de conducta que no existe fuera de esa regla ${ }^{22}$. Naturalmente,

${ }^{19}$ H. Kelsen, Teoría General del Derecho y del Estado (1945), trad. E. García Máynez, México, UNAM, $2^{\text {a }}$ ed. 1983, p. 170 y Teoría pura del Derecho, cit., pp. 68-69. Sobre las distintas interpretaciones que Kelsen ofrece de las normas de competencia, R. Hernández Marín, Historia de la Filosofia del Derecho contemporánea, Madrid, Tecnos, 1986, pp. 122 ss.

A. Ross, Sobre el Derecho y la Justicia (1958), trad. G. Carrió, Buenos Aires, Eudeba, 1970,p. 32.

G. H. von Wright, Norma y Acción: una investigación lógico (1963), trad. P. García Ferrero, Madrid, Tecnos, 1979, pp. 200 ss. 1996.

${ }^{20}$ Como es obvio, tomo la expresión de M. Atienza y J. Ruiz Manero, Las piezas del Derecho, Barcelona, Ariel,

${ }^{21}$ Por ejemplo, C. E. Alchourrón y E. Bulygin, «Definiciones y normas», en Análisis lógico y Derecho, cit., pp. 439 ss.

22 J. Searle, Actos de habla: ensayo de filosofia del lenguaje (1969), trad. L. M. Valdés, Madrid, Cátedra, $3^{\mathrm{a}}$ edic. 1990, pp. 42 ss. No obstante, en la literatura jurídica el término «regla constitutiva» recibe diferentes significados, aunque aquí puede prescindirse de los mismos; sobre los distintos significados en lo, diferentes autores, y en particular en la propia obra de Searle, R. Guastini, "Teorie delle regole costitutive», Rivista internazionale di filosofia del 
denominar «conceptualista» o «definicional» a esta posición es hacer una descripción simplificadora del asunto, pues dentro de ella se incluyen concepciones algo diferentes. En esta posición se ubicaría Hart, quien, pese a no decir expresamente que las normas que confieren potestades sean «definiciones», resalta su carácter definicional al asimilarlas a las «reglas de juego». Y otro tanto cabe decir del Ross de 1968, que -como J.Searle- distingue entre reglas regulativas y constitutivas, adscribiendo a esta última categoría las reglas de competencia. Además, en favor del carácter conceptual o definicional de las normas de competencia se decantan también C. Alchourrón y E. Bulygin; y, en análogo sentido, R. Hernández Marín las considera disposiciones cualificatorias que atribuyen la calificación de «válidos» a los enunciados que tengan una determinada propiedad: que hayan sido creados por un órgano siguiendo un cierto procedimiento y que versen sobre determinada materia ${ }^{23}$.

Por último, hay quienes entienden que las normas que confieren poderes no tienen carácter deóntico, pero tampoco definicional o conceptual, sino que son enunciados anankástico-constitutivos ${ }^{24}$ que pueden usarse como reglas técnico-constitutivas, reglas que dicen qué hay que hacer si queremos obtener un determinado resultado normativo. Por eso, a diferencia de las definiciones tales reglas constituyen razones para actuar, pero a diferencia de las normas regulativas, de donde derivan imperativos categóricos, operan como imperativos hipotéticos.

Con el fin de analizar cuáles de las NSPJ condicionan la existencia (y no sólo la validez) de los actos y normas cuya creación disciplinan, la polémica que acaba de mencionarse se muestra por un lado insuficiente y por otro

diritto, 1983. Además, sobre las reglas constitutivas puede verse A. G. Conte, «Materiali per una tipologia delle regole», Materiali per una Storia della cultura giuridica, 1985; R Guastini, «Six concepts of constitutive rules», Rechstheorie, 10, 1986; C. Alarcón, Normas y paradojas, Madrid, Tecnos, 1993, pp. 15 ss.; N. Bobbio, «Norma» (1980), ahora en Contributi ad un dizionario giuridico, Turín, Giappichelli, 1994.

${ }^{23}$ Las referencias del texto, en H. L. Hart, El concepto de Derecho (1961 ), trad. G. Carrió, México, Editora Nacional, 1980. Como «reglas de juego» las concibe también G. Robles, Las reglas del Derecho y las reglas del juego, UPM, 1984.

A. Ross, Directives and Norms, Londres, Routledge \& Kegan Paul, pp. 54 ss.

C. Alchourrón y E. Bulygin, «Definiciones y normas», cit., pp. 461 ss.; E. Bulygin, «Sobre las normas de competencia», en Análisis lógico y Derecho, cit., pp. 485 ss. y «Algunas consideraciones sobre los sistemas jurídicos», DOXA, 9 (1991).

R. Hernández Marín, El Derecho como dogma, Madrid, Tecnos, 1984, pp. 38 ss.

${ }^{24}$ Se trata de reglas cuya estructura es: «si se verifica el estado de cosas X y se realiza la acción Y, se produce el resultado R», M. Atienza y J. Ruiz Manero, «Sulle regole che conferiscono poteri», en Analisi e Diritto. 1994, Turín, Giappichelli, 1994, pp. 69 ss., en especial pp. 71-72. También J. Aguiló entiende que las normas que confieren poderes ni tienen carácter deóntico ni pueden ser asimiladas a las definiciones, «Sobre definiciones y normas», Doxa, no 8 (1990), pp. 277 ss. 
irrelevante. Insuficiente porque bajo el rótulo de «normas que confieren poderes» o «normas de competencia» se incluyen tipos diferentes de NSPJ que plantean también problemas diferentes o que, en todo caso, no pueden sin más ser asimilados. Irrelevante porque calificar esas normas como definiciones, o reglas constitutivas o conceptuales, o reglas regulativas es indiferente de cara a la distinción entre «inexistencia» e «invalidez», en los términos en que hemos planteado aquí el binomio. Primero, porque, como afirma R. Guastini, las divergencias entre las distintas teorías sobre la naturaleza de las normas de competencia nacen de interpretaciones contrastantes a partir de los enunciados jurídicos analizados ${ }^{25}$. Y segundo, y aun obviando este problema, porque tales polémicas ocultan o no muestran lo que, por lo que hace a nuestro tema, tiene verdadero interés: cómo saber cuáles son las NSPJ cuya infracción provoca la inexistencia, en el sentido de permitir la inaplicación por parte del juez. En efecto, aunque una teoría de las reglas que confieren poderes (NSPJ) debe dar cuenta de la distinción conceptual entre la inexistencia de un acto o norma y su simple irregularidad ${ }^{26}$, y en esta medida acaso sea más acertado calificarlas corno reglas constitutivas que como permisos, en lo que aquí interesa lo importante no es sólo saber si la infracción de una cierta NSPJ ha de entenderse conceptualmente como inexistencia, sino también (y sobre todo) si esto conlleva un particular régimen de invalidación (la inaplicación) para la norma inexistente. Nada de esto, sin embargo, se deduce de las mencionadas concepciones sobre las normas de competencia, que tan sólo se ocupan de su estructura lógica; tal vez porque -como ya se señaló- el régimen de validez y el de invalidación deban ser concebidos como cuestiones independientes.

No obstante lo dicho, la mayoría de los intentos para distinguir entre inexistencia e invalidez se articulan sobre la doble naturaleza de las NSPJ. Cierto que tales planteamientos no presentan las insuficiencias de las teorías sobre las normas de competencia, por cuanto distinguen entre las diferentes clases de NSPJ y abordan la figura de la inexistencia precisamente como un particular régimen de invalidación. Pero han de hacer frente a otros problemas de difícil (cuando no imposible) solución. Veamos ahora algunos de ellos.

\section{2) ¿Dos clases de reglas sobre la producción jurídica?}

Admitamos, por simplificar, que las NSPJ que condicionan la existencia son las reglas constitutivas $^{27}$, entendiendo por tales las que establecen las

\footnotetext{
${ }^{25}$ Tales enunciados jurídicos pueden ser interpretados como permisos, definiciones, reglas constitutivas, etc., R. Guastini, «In tema di norme sulla produzione giuridica», Analisi e Diritto. 1995, Turín, Giappichelli, 1995, p. 311.

${ }^{26}$ M. Atienza y J. Ruiz Manero, «Adversus pompeyanos...», cit., p. 238.

${ }^{27}$ Esta simplificación no parece forzada si admitimos -como se ha indicado- que por vía interpretativa es posible reconducir todas las NSPJ a esta categoría (vid, nota 25). Por lo
} 
condiciones para «reconocer» un acto o norma como perteneciente al tipo de fuente del que se reclama (ley, reglamento, ley autonómica, etc.). Un intento de adscribir la inexistencia a la violación de NSPJ que son reglas constitutivas es el que, desde la teoría del Derecho, ha realizado R. Guastini, quien propone una distinción entre ambos conceptos que puede resumirse como sigue:

«Una norma existe "en” un ordenamiento jurídico -o pertenece al mismo- si, y sólo si, ha sido no solamente formulada (como por ejemplo las normas de un proyecto de ley), sino además «puesta», o sea deliberada y emanada (así como publicada), de conformidad con al menos algunas de las normas sobre la producción jurídica propias del ordenamiento». En otras palabras, es suficiente que sea efectivamente formulada y emanada (o promulgada) «conforme (no a todas, sino) sólo a algunas de las normas que disciplinan su creación» ${ }^{28}$.

Pese a la claridad de la formulación, el problema reside en saber cuáles son esas NSPJ cuya infracción da lugar al vicio de inexistencia.

Como ya se dijo, pueden distinguirse cuatro grandes tipos de NSPJ: a) las que confieren a un sujeto competencia para crear cierto tipo de normas, de cuya infracción resulta un vicio de incompetencia formal; b) las que disciplinan el procedimiento para ejercer la competencia normativa, de cuya infracción resulta un vicio deforma o procedimiento; c) las que limitan o delimitan el ámbito material de ejercicio de una competencia normativa, de cuya infracción resulta un vicio de incompetencia material; d) las que limitan el contenido dispositivo de las normas creadas, cuya infracción provoca un vicio sustantivo o material.

En la interpretación de R.Guastini no queda claro cuáles de estas NSPJ traducen auténticas condiciones de existencia jurídica de las fuentes a las que van referidas; no obstante, parecen ser las primeras y sólo algunas de las segundas. Las normas que confieren competencias, según esta opinión, no son normas en sentido estricto; no pueden ser «violadas» ni «observadas», sino que incorporan definiciones o reglas constitutivas, y justamente por ello una «ley» que se separe de ellas no será propiamente una ley inválida, sino inexistente ${ }^{29}$. Más complicado es el caso de los vicios de procedimiento,

demás, como tales reglas deben aparecer en el definiens de una eventual definición de la actividad (o norma) de que se trate, hablaremos de reglas constitutivas o definiciones, indistintamente.

28 R. Guastini, «Ordinamento gitiridico», Digesto, IV Ed., vol. X Pubblico, UTET, Torino, 1995, pp. 8 y 16 (separata).

${ }^{29}$ R. Guastini, Le fonti del diritto e l'interpretazione, Turín, Giuffrè, 1993, p. 51. En un trabajo posterior precisa que «un vicio de incompetencia formal de una ley... podría ser reconocido no sólo por la Corte Constitucional, sino por cualquier juez», Distinguendo..., cit., p. 274. 
donde «no parece posible trazar una precisa línea divisoria entre la invalidez... y la inexistencia», dado que tampoco «es claro si las normas que disciplinan el ejercicio de una competencia normativa deben considerarse... normas «constitutivas» (y por tanto definiciones) $»^{30}$. Por el contrario, tanto las normas que limitan o delimitan las competencias materiales como lasque condicionan el contenido sustantivo parecen ser auténticas normas (no definiciones), y por ello su violación da lugar a invalidez, no a inexistencia. En suma, el vicio de incompetencia formal y el de procedimiento (aunque éste no siempre) darían lugar a la»inexistencia», mientras que el vicio de incompetencia material y el sustantivo (y a veces el de procedimiento) darían lugar a la «invalidez». La distinción entre inexistencia e invalidez parece que se establece en base al propio carácter de las NSN: la infracción de definiciones o reglas constitutivas daría lugar a la inexistencia; la infracción de las normas regulativas, a la invalidez.

El binomio invalidez-inexistencia no siempre se articula -o no expresamente- en tomo a la distinción entre definiciones o normas constitutivas y normas regulativas, pero se establece también en función de una tipología de normas que en la práctica conduce a resultados equivalentes. Así sucede, por ejemplo, en la literatura jurídica constitucionalista, donde -en líneas generales- la explicación es la siguiente: dan lugar a la «inexistencia» los vicios formales, esto es, los de incompetencia formal y algunos de procedimiento; ocasionan la «invalidez» (de normas ya existentes) los vicios materiales, es decir, los de incompetencia material y los sustantivos $^{31}$. Y una posición similar a ésta, ya en el ámbito de la teoría jurídica, es la de L. Ferrajoli, quien, aunque con terminología diferente, viene a sostener también la doble naturaleza de las NSPJ: una norma se considera vigente -existente, hemos dicho hasta aquí- cuando respeta las exigencias formales de producción, mientras que será válida cuando además observe los requisitos sustantivos o de contenido. Por eso, cuando la ineficacia de un sistema de normas acerca de la producción «llegue al punto de no respetar siquiera las

${ }^{30}$ Le fonti..., cit., pp. 52-53. En Distinguendo... afirma Guastini que «por lo general, la violación de una sola norma de procedimiento implica invalidez (y no inexistencia), mientras la (improbable) violación de todas las normas procedimentales produce seguramente la inexistencia», cit., p. 275.

${ }^{31}$ Así, la falta de aprobación del texto legislativo por las Cámaras, o la no promulgación del texto aprobado por éstas, o la disconformidad entre el texto aprobado y el definitivamente promulgado son ejemplos recurrentes de inexistencia; mientras que el exceso del ámbito competencial asignado al legislador o la violación de disposiciones constitucionales atinentes al contenido dispositivo de la ley son típicos ejemplos de invalidez. Vid., por ejemplo, C. Esposito, La validità delle leggi (1934), reimp. Milán, Giuffrè, 1964, pp. 280 ss.; M. Sandulli, «Legge (vizi della)», Novis. Dig. It., Turín, UTET, y ed. 1957, IX, p. 648; L. Pastor Ridruejo, «Aplicación de la ley y control de constitucionalidad», El Tribunal constitucional, cit., III, p. 2021. 
condiciones formales de validez del acto de producción normativa, diremos que la norma no ha sido producida y por consiguiente no está vigente, no existe». En cambio, cuando la norma presente únicamente vicios sustantivos, «diremos que no es válida, aunque esté vigente, o exista $\iota^{32}$.

Como puede apreciarse, en todos los casos enunciados la figura de la «inexistencia» se vincula a la infracción de un tipo de NSPJ: unas veces se identifican con las normas «formales» (o que fijan condiciones formales de validez); otras con las definiciones o las reglas constitutivas. No obstante, las dos explicaciones muestran una cierta superposición de criterios. Por un lado, tienden a identificarse como normas constitutivas las que fijan condiciones formales de validez, por lo que ambos criterios conducen en la práctica a resultados equivalentes. Por otro, quienes cifran la clave de la inexistencia en la infracción de normas formales parecen considerar que -entre todas las NSPJ- sólo éstas incorporan condiciones fuera de las cuáles el acto o norma no es recognoscible como parte del tipo de fuente del que se reclame; podría decirse que, en el fondo, se trata siempre de una misma explicación teórica: la infracción de definiciones o reglas constitutivas.

Apelar al carácter constitutivo de las NSPJ como criterio de identificación de la existencia jurídica resulta inobjetable desde un punto de vista conceptual, pues -por definiciónla infracción de una regla constitutiva provoca un vicio de inexistencia, dado que impide reconocer el acto o norma como parte del sistema. Ahora bien, esta postura plantea al menos dos problemas, uno de índole práctica y otro referente a la composición del ámbito de las NSPJ que son reglas constitutivas.

El problema práctico reside en que no resulta nada fácil discernir cuándo se ha violado una definición o regla constitutiva, dando lugar a la inexistencia, y cuándo una norma que tan sólo establece limitaciones a la actividad legislativa, dando lugar a la invalidez. Por ello, en este sentido, Alchourrón y Bulygin señalan que la línea divisoria entre las definiciones por un lado y las normas por otro es hasta cierto punto arbitraria, pues no existe un criterio que permita decidir en todos los casos frente a un artículo determinado si éste expresa una definición o una norma $^{33}$. Es evidente, en efecto, que una ley creada con el concurso de una sola Cámara legislativa no es más que una «apariencia» de ley, una norma inexistente; como tal vez fuera asimismo evidente que una ley orgánica aprobada sin la mayoría reforzada necesaria sería una ley inexistente, naturalmente en tanto que ley orgánica. Por otro lado, parece que una ley autonómica cuya constitucionalidad

32 L. Ferrajoli, Derecho y razón. Teoría del garantismo penal (1989), trad. P. Andrés, A. Ruiz Miguel, J C. Bayón, J. Terradillos y R. Cantarero, Madrid, Trotta, 1995, p. 359.

${ }^{33}$ C. Alchourrón y E. Bulygin, «Definiciones y normas», cit, pp. 460-61. 
pueda discutirse por regular materias de competencia estatal sería una ley existente, aunque tal vez termine siendo declarada inconstitucional; como también parece seguro que una ley de la que pueda discutirse su conformidad con el régimen constitucional de derechos fundamentales sería una ley existente, aunque quizá termine siendo declarada inconstitucional. Ahora bien, entre los dos primeros casos y los dos últimos puede existir una amplia gama de supuestos en los que ya no quepa establecer con claridad si se trata de normas existentes o inexistentes; esto es, si se ha violado una regla constitutiva o un simple límite a la actividad normativa ${ }^{34}$.

El vicio de incompetencia formal (tal vez siempre) y el vicio de forma (en algunos casos) pueden dar lugar a la inexistencia; pero no ha de ser necesariamente así. Por ejemplo, con referencia al segundo de ellos, si se cuestiona la inconstitucionalidad de una ley por un simple error en el recuento de la mayoría parlamentaria exigida para su aprobación, difícilmente se tendría la ley por inexistente ${ }^{35}$. Por su parte, el vicio de incompetencia material y el sustantivo no provocarán en la mayoría de los casos la inexistencia de la norma; pero no siempre tiene por qué ser así. Por ejemplo, con respecto al primero de ellos, una ley autonómica que estableciera regulaciones sobre la organización del Ejército probablemente sería considerada inexistente, porque ésta es una materia de clara competencia estatal; como quizá sucedería lo mismo con un reglamento municipal que impusiera penas de prisión. Y asimismo, con respecto al segundo, es probable que pudiera considerarse inexistente una ley penal que estableciera la pena de muerte. Por lo demás, no se trata sólo de que en la práctica sea difícil determinar qué reglas son definiciones -o partes de definiciones- y cuáles no. Es que hay quien mantiene incluso que el incumplimiento de los requisitos exigidos por una definición provoca la nulidad del acto o norma definida, pero nulidad «en sus diversos matices, que van desde el acto inexistente y nulidad absoluta hasta la nulidad relativa y anulabilidad ${ }^{36}$. En otras palabras, y dado que son cuestiones independientes, como ya adelantamos en el

\footnotetext{
${ }^{34}$ Con todo, algunas de las «evidencias» de que se habla en el texto son premeditadamente problemáticas. Así, una regulación que adopta la forma ordinaria, debiendo adoptar la orgánica, parece que presenta un vicio de procedimiento, ya que no se observaron los requisitos de mayoría reforzada, aunque también puede concebirse como un vicio de incompetencia material, dado que el legislador ordinario excedió su ámbito competencial; pero, sea como fuere, parece casi seguro que un Juez considerará la norma como inválida y en ningún caso como inexistente.
}

35 Es más, se sostiene que hay que distinguir entre las meras irregularidades procedimentales sin eficacia invalidante y los vicios invalidantes; pero aún dentro de estos últimos, entre los vicios que admiten sanación y los que no. Sobre ello, P. Biglino, Los vicios en el procedimiento legislativo, Madrid, CEC, 1991.

${ }^{36}$ C. Alchourrón y E. Bulygin, «Definiciones y normas», cit., p. 463. 
epígrafe I, la simple identificación de vicios de inexistencia y de invalidez no conlleva necesariamente el establecimiento de distintos regímenes de invalidación.

Por otra parte, y éste es el segundo problema enunciado, ¿qué es lo que hace pensar que sólo forman parte de la definición de ley las normas de competencia normativa y de procedimiento y no, en cambio, las de competencia material y de contenido? En un sistema jurídico en el que la coherencia con la Constitución se establece como criterio de validez de una ley, bien puede sostenerse que la definición de ley no comprende las leyes incoherentes. Y otro tanto cabría decir del requisito de competencia material. Por lo demás, me parece que el propio Guastini tiene presente esta circunstancia al afirmar que no puede trazarse una estricta separación entre inexistencia e invalidez porque «no es posible decir con precisión a cuáles (y a cuántas) normas sobre la producción jurídica debe ser conforme una norma para superar la barrera de la "inexistencia" sin alcanzar sin embargo la validez» ${ }^{37}$. En suma, en ausencia de una diferenciación normativa entre inexistencia e invalidez, la distinción entre ambas hipótesis es «insuperablemente problemática» ${ }^{38}$.

Una vez abandonado el camino de la dicotomía entre definiciones y normas, parece que nuestra distinción depende de las determinaciones del Derecho positivo o, cuando menos, de las posibilidades hermenéuticas que éste ofrezca. Por ello se trata de ver ahora si cabe aventurar algún criterio que permita postular un reconocimiento por el orden jurídico, ya en el plano normativo, ya, si es posible, en el marco de la interpretación.

\section{3) Ventajas y dificultades del concepto de inexistencia}

La inexistencia -ya se señaló- se traduce en la posibilidad de inaplicación de la norma por parte de los operadores jurídicos, con independencia del régimen general de invalidación establecido, así como en el reconocimiento de plenos efectos retroactivos a una eventual sentencia de inconstitucionalidad; sencillamente, una norma inexistente no precisaría someterse a un juicio específico de valide $z^{39}$, y, de someterse, la declaración de inconstitucionalidad tendría efectos ex tunc. En esto consiste la función de la inexistencia, en instaurar un particular régimen de invalidación para ciertos

\footnotetext{
${ }^{37}$ R. Guastini, «ordinamento giuridico», cit., p. 16.
}

${ }^{38}$ G. Zagrebelsky, La Giustizia costituzionale, Bolonia, II Mulino, 2a ed., 1988, p. 164.

${ }^{39}$ Es más, se sostiene incluso que la inexistencia conlleva la imposibilidad de una intervención ad hoc del órgano encargado de controlar la constitucionalidad, pues para ello es necesario que la norma exista. En este sentido, la Corte cost. italiana, en sentencia 152/1982, afirmaba que «es contradictorio asumir la radical inexistencia de la ley y al mismo tiempo dirigirse a la Corte para que declare su inconstitucionalidad». 
vicios al margen del régimen general de invalidación instaurado en el sistema, que obviamente es distinto, pues si no, no hay cuestión. Creo que esta función, además, muestra un fundamento serio: es propio del sistema, en cuanto sistema «jurídico», defenderse frente a los elementos extrajurídicos o extra ordinem, expulsándolos de su seno lo más rápida y eficazmente Posible. Pues bien -si dejamos de lado los sistemas de control preventivo de constitucionalidad-, la defensa más rápida y eficaz es la que realizan difusamente los jueces ordinarios inaplicando la ley inconstitucional. Por ello, una razón fuerte (tal vez la única) que apoya el régimen de la inexistencia es la necesidad de reaccionar rápida, eficaz y vigorosamente contra los elementos extraños al ordenamiento ${ }^{40}$.

Ahora bien, queda aún por determinar en base a qué elemento puede establecerse esa distinción; es decir, cuál es el criterio que permite configurar la «inexistencia» como distinta de la «invalidez». Me parece que en la elección de este criterio han de tenerse en cuenta dos exigencias. En primer lugar, el criterio debe ser coherente con la función que la inexistencia está destinada a cumplir, y como esta función consiste en establecer un particular régimen de invalidación orientado a reaccionar de un modo expeditivo frente a aquellos actos o normas que resultan más groseramente irregulares, el criterio tiene que apelar a una clase de vicios que justifiquen esa rápida actuación. En segundo lugar, la inexistencia así construida no debe dejar sin eficacia al régimen general de invalidación establecido en el sistema. En efecto, tal vez pudiera argumentarse que el objetivo al que se endereza la inexistencia es perseguible en todos los casos de invalidez; es decir, que lo óptimo sería siempre una actuación rápida y eficaz frente a los elementos extrajurídicos. Ello puede ser cierto, pero es necesario cohonestar este objetivo con otros valores que el sistema ha querido proteger al instaurar un régimen de invalidación distinto a la inexistencia; por ejemplo, en los casos de jurisdicción constitucional concentrada, el privilegio de la ley, de las mayorías parlamentarias en definitiva.

Teniendo en cuenta estas dos exigencias, parece que tan sólo cabe pensar como criterio de la inexistencia en la manifiesta e indubitada inconstitucionalidad, dado que es éste un elemento que justifica la inmediata ineficacia (inaplicación) de la norma en el sistema y que, al mismo tiempo, no cancela el régimen general de invalidación establecido. Ciertamente se trata de un criterio impreciso, elástico y, en definitiva, débil, pero creo que

${ }^{40}$ Acertadamente, a nuestro juicio, señala G. Zagrebelsky que la inexistencia de la ley, en cuanto posibilidad de inaplicación de la misma por parte de cualquier juez, no es un problema de coherencia, sino de «defensa del ordenamiento frente a hechos externos (no frente a un vicio interno), tarea que no puede ser monopolio de la Corte, sino que debe desarrollarse difusamente», La Giustizia costituzionale, cit., p. 165. 
también se halla latente en las elaboraciones ya examinadas, pues la vinculación de la inexistencia a la infracción de las normas que establecen condiciones formales de invalidez (o de las normas constitutivas, pero tendiendo a identificar éstas con las que establecen condiciones formales de validez), parece obedecer en el fondo a la «facilidad» para detectar la infracción. Esto me parece particularmente evidente en la posición de L. Ferrajoli, que al vincular el binomio inexistencia-invalidez al carácter formal o material del vicio, lo hace equivalente al tipo de juicio que comporta la verificación del vicio: simple (y fácil) averiguación empírica, en el primer caso; juicio valorativo, en el segundo ${ }^{41}$. En suma, diremos que una norma es inexistente cuando carece en absoluto de una apariencia de validez; es decir, cuando su invalidez sea manifiesta, evidente y fácilmente recognoscible; cuando no hay dudas de que, llegado el caso, la norma será declarada inválida por el órgano competente.

Aunque con terminología parcialmente diferente, esta opinión cuenta con algún apoyo doctrinal. Así, hay quien ha cifrado la «irrecognoscibilidad» de un acto o norma (su inexistencia) no en la infracción de específicas NSPJ, sino en su «incompatibilidad irreversible o irreparable» con las normas, sean del tipo que sean, que establezcan condiciones de validez stricto sensu. En concreto, con referencia a un supuesto particularmente problemático como es el de las normas de procedimiento, «si un acto normativo es recognoscible como tal, independientemente de la conformidad de su procedimiento de formación a las normas que lo regulan, será existente $\rangle^{42}$. $\mathrm{Y}$ en relación con las normas que limitan el objeto o el contenido normativo, supuesto casi sistemáticamente excluido del ámbito de condiciones de la existencia, también «es posible que -excepcionalmente- esas normas se erijan en condiciones necesarias de la existencia de otras normas... Son hipótesis extremas, pero no por ello inimaginables. En estos casos, la incompatibilidad... es irreversible o irreparable, y no permite una eficacia precaria de la norma en el ordenamiento» ${ }^{43}$. En resumen, llamamos inexistencia a los

${ }^{41}$ Los juicios sobre la vigencia son juicios de hecho que tan sólo requieren una averiguación empírica, mientras que los juicios de validez ostentan un carácter valorativo. Derecho y razón, cit, pp. 874 ss. Con todo, lo cierto es que Ferrajoli no extrae ninguna consecuencia diferenciadora en relación con el régimen de invalidación de una norma inexistente y de una norma inválida; al contrario, parece que el juez ordinario sólo vendría llamado a aplicar las normas que reúnan tanto las condiciones de validez como de vigencia (pp. 873 y 926).

${ }^{42}$ F. Modugno, «Validità», Enciclopedia del Diritto, Milán, Giuffrè, 1993, p. 45.

${ }^{43}$ Ibidem, p. 46. Así, una norma que prevea la pena de muerte, o que suprima la Corte constitucional. Pero los supuestos no tienen por qué ser tan extraordinarios, pues cabe pensar que lo mismo sucedería «en los casos en que la Constitución haga referencia a términos o nociones de arraigado sentido común». Más aún, con mucha frecuencia la Constitución fija términos inderogables o datos y cálculos numéricos absolutamente inequívocos, cuya modificación expresa debería dar lugar a la nulidad-inexistencia de la ley que los hubiese dispuesto», F. Modugno, «Legge (vizi della)», en Enciclopedia del Diritto, Milán, Giuffrè, 1973, p. 1027. 
vicios que prevemos que determinarán la invalidez con toda seguridad o, lo que es igual, a la manifiesta e indubitada inconstitucionalidad. Pero esta afirmación requiere algunas consideraciones adicionales.

La primera observación hace referencia al carácter del juicio de inexistencia. Dictaminar sobre la existencia de una norma resulta en parte idéntico a dictaminar sobre su validez; se trata, pues, de un juicio descriptivo destinado a constatar si determinada norma reúne las condiciones de pertenencia establecidas en el sistema. Sin embargo, el juicio de inexistencia presenta además una dimensión en cierto modo predictiva, porque requiere «aventurar» que ese vicio es de tal naturaleza o magnitud que, con toda seguridad, conducirá a la declaración de invalidez. Ahora bien, interesa subrayar que esa dimensión predictiva requiere algún respaldo normativo, pues, desde un punto de vista teórico, el juicio de inexistencia no se distingue en nada del juicio de invalidez: o las NSPJ presentan claramente dos fisonomías distintas (reglas constitutivas o de existencia y reglas de comportamiento o de validez), y ya hemos formulado una respuesta negativa, o irremediablemente validez y existencia aluden a unas mismas condiciones de pertenencia ${ }^{44}$.

A este respecto, la construcción de la idea de inexistencia de la ley y el consiguiente reconocimiento al juez ordinario de una facultad de inaplicación resulta sumamente complicado en un modelo de jurisdicción concentrada, como el español. Y no porque el juez ordinario no sea también un juez de constitucionalidad, que lo es en algunos casos. El problema reside en que -según interpretación que creo casi unánime- la existencia de la cuestión de inconstitucionalidad excluye con carácter absoluto que el juez ordinario pueda decidir sobre la validez de una ley ${ }^{45}$; aunque, eso sí, si la ley es preconstitucional se admite el juego del esquema derogatorio. Con todo, y aunque a la vista de tal unanimidad la interpretación puede parecer forzada, lo cierto es que el tenor literal de la LOTC permitiría, a mi entender, un posible juicio de inexistencia por parte del juez ordinario. Dice su art. 35.1 que

${ }^{44}$ Otra cosa es que se tome como punto de partida un concepto predictivo de validez, según admite alguna interpretación de A. Ross, algo que no se ha hecho en este trabajo. Vid. sobre ello E. Pattaro, Filosofía del Derecho. Derecho. Ciencia jurídica (1978), trad. J. Iturmendi, Madrid, Reus, 1980, pp. 257 ss.

45 Vid., por ejemplo, J. Almagro, Justicia constitucional, cit., p. 427; J. Arozamena, «El recurso de inconstitucionalidad», cit., p. 146; J. González Pérez, «La cuestión prejudicial de inconstitucionalidad», El Tribunal Constitucional, cit., II, p. 1224; J. M. Sala, «Consideraciones sobre la cuestión de inconstitucionalidad», El Tribunal Constitucional, cit., III, p. 2453; P. Pérez Tremps, Tribunal Constitucional y Poder Judicial, Madrid, CEC, 1985, pp. 126 ss.; F. Rubio, «Sobre la relación entre Tribunal Constitucional y Poder Judicial en el ejercicio de la jurisdicción constitucional», La forma del poder (estudios sobre la Constitución), Madrid, CEC, 1993, p. 474. 
cuando el juez considere que una ley aplicable al caso y de cuya validez dependa el fallo «pueda ser contraria a la Constitución, planteará la cuestión al Tribunal Constitucional...». Pues bien, la expresión «pueda ser», que sugiere por cierto un juicio predictivo, supone la existencia de una duda, pues es claro que si el juez no duda porque considera seguro que la ley es constitucional no precisa plantear cuestión alguna. Pero, ¿y si su seguridad versa no sobre la validez de la ley, sino sobre su invalidez?, ¿si carece de toda duda, pero no de que la ley es constitucional, sino, a la inversa, de que es groseramente inconstitucional?, ¿cabría pensar entonces en la pura y simple inaplicación de una ley que se juzga no ya inválida, sino inexistente? Desde luego -y ya que hablamos de juicios predictivos- no parece que hoy por hoy sea viable una respuesta afirmativa ${ }^{46}$. Con todo, cabría pensar en una modificación normativa en el sentido indicado; más aún, cabría pensar en una interpretación favorable del Tribunal Constitucional sobre el argumento de que, para plantear cuestión de inconstitucionalidad, la ley debe ser al menos recognoscible como tal, esto es, como elemento intra ordinem. Todo lo cual resultaría coherente con el proceso de acercamiento entre los modelos norteamericano y europeo de justicia constitucional.

Por otra parte, la construcción de una categoría de inexistencia o manifiesta inconstitucionalidad debería conducir también a una fórmula de control más vigorosa, que no debería consistir, por tanto, sólo en la sustitución del modelo concentrado por el difuso, sino en una especie de modelo mixto donde coexistan ambos: posibilidad de inaplicación inmediata en los casos de manifiesta inconstitucionalidad y posibilidad, al mismo tiempo, de una intervención ad hoc del Tribunal constitucional ${ }^{47}$ que, además, garantizase sin paliativos los efectos ex tunc de la declaración de inconstitucionalidad (inexistencia).

\footnotetext{
${ }^{46}$ Más permisiva parece la doctrina italiana. «En nuestro ordenamiento, escribe Guastini, el juez ordinario... puede inaplicar una ley «inexistente» -un documento que ni siquiera sea recognoscible como ley- sin que necesite remitir la cuestión a la Corte constitucional», Le fonti del diritto.... cit., p. 53, donde cita la sentencia 152/1982 Corte Const. en dicho sentido.

${ }^{47}$ En análogo sentido. G. Zagrebelsky discrepa de la postura mantenida en la aludida sentencia 152/1982 Corte Cost. y sugiere para la inexistencia la misma solución que se adoptó para la inconstitucionalidad sobrevenida: «jurisdicción de la Corte constitucional (con fines de certeza), sin excluir, en los casos más evidentes, el poder de inaplicación inmediata por parte de cualquier juez», La giustizia costituzionale, cit., p, 164.

También M. Atienza y J. Ruiz Manero, aunque desde su visión de la inexistencia como infracción de las «reglas que confieren poderes», afirman que cuando «claramente no se haya realizado el acto normativo (por ejemplo, porque el sujeto no estaba cualificado para realizarlo) obviamente no existe posibilidad de impugnación. Pero es evidente que las reglas que confieren poderes pueden presentar una trama abierta, un halo de penumbra, capaz de hacer controvertible si el acto normativo ha sido o no realizado; con la consecuencia de que los sistemas jurídicos bien pueden prever la posibilidad de impugnación también en estos casos», «Adversus Pompeyanos...», cit., p. 242, subrayado añadido.
} 
En concreto, y con referencia a este último aspecto, me parece que en los casos de leyes inexistentes no se debería permitir la conservación de ninguna situación jurídica nacida a su amparo, tal vez ni siquiera de la cosa juzgada que hoy establece el art. 40 LOTC. Al fin y al cabo, si en un sentido los Tribunales Constitucionales se han orientado por motivos prácticos hacia la formación de una jurisprudencia prospectiva, parece razonable que, en sentido contrario y por idénticos motivos, se orienten también hacia una jurisprudencia plenamente retroactiva. No parece exagerado pretender que un vicio «manifiesto» no deba dejar rastros en el ordenamiento.

Junto a estos problemas que pudiéramos llamar normativos, la construcción de un concepto de inexistencia distinto al de invalidez presenta también una dificultad práctica importante: la de configurar los signos que hagan posible predecir que una norma será declarada inválida. Desde luego, no existen reglas formales que permitan orientar una tal predicción, pero creo que puede afirmarse que cuanto mayor es el esfuerzo interpretativo necesario para detectar un vicio, menor es la seguridad de que éste se declare. En efecto, el vicio se manifiesta con más evidencia cuando las condiciones de validez de las normas se hallan altamente formalizadas. Por ello, la evidencia disminuye cuando se está ante condiciones materiales de validez, ya que entonces se requiere un alto grado de interpretación normativa, y aumenta cuando se está ante condiciones formales de validez, porque entonces apenas se requiere interpretación ${ }^{48}$.

Así, el vicio de incompetencia formal resultará siempre más o menos claro, pues sólo hay que comprobar si el sujeto que produjo la norma coincide con aquél al que una norma superior atribuyó la competencia para crear ese tipo de normas; lo que, además, en el caso de sujetos normativos que son órganos del Estado, no puede revestir demasiadas dudas: no hay que hacer una comprobación ad personam, sino sólo formal ${ }^{49}$.

${ }^{48}$ Creo que un planteamiento parecido subyace a la crítica de M. Jori a la distinción de L. Ferrajoli entre inexistencia o falta de vigencia (fundada en la infracción de condiciones formales de validez) e invalidez (fundada en la infracción de condiciones materiales de validez). Según Jori, en ambos casos lo que se infringen son requisitos establecidos por normas superiores, y por tanto no hay una diferencia sustantiva entre ellas. Si la distinción puede parecer correcta es porque «de hecho las llamadas normas formales (por lo general normas de competencia o de procedimiento) son casi siempre semánticamente más precisas y rigurosas que las otras». Pero -añade- manifiestan «los mismos problemas de indeterminación semántica, discrecionalidad interpretativa y referencias a parámetros valorativos». Incluso -señala en nota a pié de página- hasta la más precisa de las normas de procedimiento puede plantear problemas interpretativos, «La cicala e la formica», Le ragioni del garantisnio. Discutendo con L. Ferrajoli, L. Gianformaggio (coord.), Turín, Giappichelli, 1993, p. 84.

${ }^{49}$ Con todo, esta hipótesis, que sería claramente de inexistencia, resulta ser también de laboratorio, al menos en una situación de normalidad en la vida del Estado: no es pensable que un Ayuntamiento dicte una «ley», sino, en su caso, un reglamento ilegal o con invasión de la reserva de ley. 
La hipótesis de vicios de procedimiento resulta sin duda más previsible, pero -en contrapartida- presenta mayores dificultades, pues las NSPJ de procedimiento son muy numerosas y no siempre puede detectarse su violación sin interpretación. Máxime si, como mantienen algunos, hay que hacer una lectura instrumental de este tipo de normas, con lo cual la invalidez por infracción de normas de procedimiento estará condicionada a la existencia de elementos no estrictamente formales ${ }^{50}$.

Esto es aún más evidente en el caso del vicio de incompetencia material. La limitación y delimitación de competencias materiales padece de una escasísima formalización en el ordenamiento. De manera que no resulta ni mucho menos fácil detectar si una fuente, al dictar una concreta regulación normativa, ha rebasado el ámbito de su competencia material. Esta es la razón por la cual, en la mayoría de los casos en que se discute si se ha respetado o no una norma de competencia material, la cuestión está lejos de ser clara y exige una interpretación de la disposición producida. Ahora bien, ello no obsta para que en un determinado supuesto, bien porque se esté ante una competencia formalmente bien delimitada (normativa, doctrinal o jurisprudencialmente), bien porque se esté ante una infracción de la competencia absolutamente grosera, el vicio de competencia se presente como evidente. Por ejemplo: una ley autonómica que contenga una regulación sobre la defensa nacional.

Por último, el vicio sustantivo es quizá el menos evidente, pues, por definición, constituye la constatación de una antinomia, por lo que es siempre necesaria una interpretación de las normas en conflicto. Esto no significa que no pueda haber casos en que la antinomia resulte evidente, casos en los que pueda afirmarse con seguridad que el órgano competente para enjuiciar la invalidez, de ser llamado a pronunciarse, declararía la presencia del vicio sustantivo y la consiguiente invalidez de la norma ${ }^{51}$. Pero tales casos serán poco frecuentes, al menos en períodos de normalidad constitucional; pensemos, por ejemplo, en una ley que estableciera la pena de muerte para tiempo de paz.

En resumen, la distinción entre inexistencia e invalidez no sirve a un designio teórico, salvo que aceptásemos la doble naturaleza de las NSPJ, por ejemplo, entre reglas constitutivas y normas imperativas; pero sí presenta un cierto interés práctico en aquellos sistemas jurídicos que establecen un modelo para la declaración de invalidez de las leyes que -a la postrerepresenta

${ }^{50} \mathrm{P}$. Biglino, Los vicios del procedimiento legislativo, cit.

51 Tal vez el ámbito propio de este tipo de supuestos sea el de aquellos «casos en que la Constitución haga referencia a términos o nociones de arraigado significado» o fije «términos inderogables o datos y cálculos numéricos absolutamente inequívocos», vid. F. Modugno, «Legge (vizi della)», cit., p. 1027. 
un privilegio para el legislador y constituye una excepción al sistema común de invalidación previsto para el resto de los actos jurídicos. Dicho interés no reside lógicamente en la posibilidad de suplantar sin más ese modelo privilegiado que se concreta en la cuestión de inconstitucionalidad, sino en la de complementarlo, siquiera como propuesta de lege ferenda, con un régimen más vigoroso de invalidación para aquellos supuestos de inconstitucionalidad más groseros que suponen, no ya una infracción de la Constitución, sino una quiebra abierta e indubitada de la misma; hipótesis que, se repute o no como de laboratorio, tampoco cabe excluir en un planteamiento general ni, por supuesto, en circunstancias de cierta anormalidad en la vida del Estado. Un régimen de invalidación por inexistencia que, al menos, debería traducirse en dos aspectos: inaplicación por parte del juez ordinario y, en su caso, sentencias plenamente retroactivas del Tribunal Constitucional.

\section{CONCLUSIONES}

1. ${ }^{\circ}$ El régimen de validez de las normas es el conjunto de reglas que establecen sus condiciones de existencia jurídica. El régimen de validez identifica (simultáneamente) el régimen de «vicios».

2. ${ }^{\circ}$ El régimen de invalidación de las normas es el conjunto de reglas que institucional izan el sistema de control de su invalidez y (paralelamente) el régimen de eficacia de la norma inválida.

3. ${ }^{\circ}$ El régimen de eficacia de los actos jurídicos declarativos de la invalidez es el conjunto de reglas que establece el tipo de eficacia (temporal) de estos actos.

4. ${ }^{\circ}$ La distinción nulidad/anulabilidad se usa (ambiguamente) para hacer referencia a cada uno de estos tres regímenes y es confusa. A veces alude al régimen de validez (vicios de nulidad o de anulabilidad), otras al régimen de invalidación (sistema difuso o concentrado) y otras al régimen de eficacia de los actos que declaran la invalidez (efectos retroactivos o prospectivos).

5. ${ }^{\circ}$ Los tres regímenes mencionados son independientes entre sí: cada sistema jurídico puede establecer una concreta combinación de los mismos.

6. ${ }^{\circ}$ No obstante, cabría plantear si -pese a la independencia entre estos tres regímeneses posible configurar en algún supuesto una conexión entre ellos a través del concepto de «inexistencia». El concepto de inexistencia aludiría así a un especial tipo de vicio (el de inexistencia), supondría un peculiar régimen de invalidación (el de la inaplicación) y su eventual declaración por un órgano «ad hoc» tendría asimismo un tipo de eficacia particular (la plena retroactividad).

7. ${ }^{\circ}$ Si se parte de un concepto de validez como existencia jurídica de una norma, la distinción entro inexistencia e invalidez carece de sentido desde 
un punto de vista teórico, salvo que se aceptase que conceptualmente existen dos clases bien diferenciadas de NSPJ. Sin embargo, la distinción entre reglas constitutivas e imperativas no parece ofrecer fundamento sólido a la configuración de la inexistencia en los términos planteados.

8. ${ }^{\circ}$ Lo anterior no obsta para que normativamente se configure la «inexistencia» identificando claramente un conjunto de vicios a los que se podría anudar un régimen propio (difuso) de invalidación, así como unos efectos particularmente vigorosos (plenamente retroactivos) para su declaración.

9. ${ }^{\circ}$ Cuando el sistema no configura normativamente la inexistencia, sólo cabe argumentar a su favor en sede doctrinal y acaso, mediante una interpretación aún no producida, también en sede jurisprudencial.

$10 .^{\circ}$ Para argumentar en favor de la inexistencia es necesario que su distinción con la invalidez tenga fundamento. A este respecto hay que decir que la inexistencia, por cuanto particular régimen de invalidación, persigue un objetivo que la justifica: proporcionar un eficaz instrumento de reacción frente a los elementos extrajurídicos.

$11 .^{\circ}$ El criterio que haya de configurar la inexistencia tiene que permitir cohonestar el objetivo que ésta persigue con las finalidades propias del régimen general de invalidación establecido; esto es, no se puede dejar sin eficacia el régimen general de invalidación.

12..$^{\circ}$ Teniendo en cuenta esta exigencia, parece que sólo cabe acudir al criterio, sin duda lábil y escurridizo, de la «manifiesta inconstitucionalidad»o «evidencia de invalidez», lo que supone un juicio predictivo acerca del carácter indiscutible de alguno de los vicios de invalidez constatados. Con una u otra terminología, este es el criterio que se desprende tanto de las aproximaciones teóricas más generales como de las construcciones dogmáticas de Derecho público.

13. ${ }^{\circ}$ La absoluta falta de apariencia de validez de una norma, ocurrirá, sobre todo, cuando los requisitos de validez estén tan altamente formalizados que la invalidez pueda ser fácilmente reconocida por cualquier operador jurídico. Por tanto, la posibilidad del juicio de inexistencia de una norma se halla en una relación inversamente proporcional al esfuerzo interpretativo necesario para constatar la existencia de un vicio en su formación o contenido. 